\title{
Trends in folic acid supplementation during pregnancy - the effect on allergy development in children
}

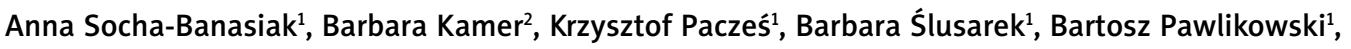 \\ Elżbieta Czkwianianc ${ }^{1}$
}

${ }^{1}$ Gastroenterology, Allergology and Pediatric Department, Polish Mother's Memorial Hospital Research Institute, Lodz, Poland ${ }^{2}$ The Academy of Business Administration and Health Sciences, Lodz, Poland

Adv Dermatol Allergol 2018; XXXV (2): 139-144

DOI: https://doi.org/10.5114/pdia.2017.68785

\begin{abstract}
Introduction: The results of some previous studies suggested that maternal folate supplementation during pregnancy may contribute to allergy development in offspring.

Aim: This study was performed to examine the influence of maternal folic acid intake prior to and during pregnancy on the development of various types of allergy in children taking into account the timing and dosage of supplemented folate.

Material and methods: The retrospective study was performed between 2010 and 2014 in 307 child-mother pairs (203 allergic children and 104 children without allergy symptoms, aged 2-72 months). Allergy diagnosis was based on medical history, physical examination, positive results of allergic tests: specific IgE and/or skin prick tests and double-blind, placebo-controlled food challenge. The data concerning maternal folate supplementation prior to and during pregnancy were obtained based on a questionnaire.

Results: Mothers of allergic children used to take folic acid more frequently in the preconception period (42.9\%), in the $1^{\text {st }}(94.1 \%)$ and the $2^{\text {nd }} / 3^{\text {rd }}(81.3 \%)$ trimester of pregnancy than mothers of the healthy ones $(30.8 \%, 82.7 \%$ and $55.8 \%$, respectively) $(p<0.05)$. Maternal intake of folate in a dosage higher than recommended $(>0.4 \mathrm{mg} /$ day $)$ was more often observed in the group of allergic subjects, especially in children with combined sensitization to food and inhalant allergens, than in the control group $(p<0.05)$.

Conclusions: Our results suggest an impact of maternal folic acid supplementation prior to and during pregnancy on allergy development in children. Further observations are required to establish the role of folate in fetal epigenetic modifications.
\end{abstract}

Key words: allergy, children, epigenetic modifications, folate supplementation, pregnancy.

\section{Introduction}

Folic acid insufficiency in pregnant women may influence the development of various congenital defects in offspring, in particular the neural tube defects (NTDs) [1]. In many countries, Poland included, folic acid is recommended to all women in a dose of $0.4 \mathrm{mg} /$ day at least one month prior to conception and up to 12 weeks post conception to prevent these defects [2-4].

Folates are involved in numerous biochemical reactions, including the process of neural tube closure in the fetus, the DNA and amino acid synthesis, and DNA methylation. The processes of nucleic acid methylation involve the attachment of methyl groups in CpG sequences. The degree of DNA methylation plays an important role in the control of gene expression [5-7]. The study performed in an animal model by Hollingsworth et al. [8] indicated that enriching the diet of female mice with methyl donors during pregnancy promotes DNA changes affecting the Th2 polarization and increasing the risk and severity of allergic airways disease in the offspring. Although the pathogenesis of atopic diseases is still not fully known, it was recognized that periconceptional period is critical for appropriate immunological programming in children [7-9]. Pregnancy is a crucial period for the fetal immune system development and regulation of Th1, Th2 and Treg balance, which is controlled by epigenetic modification. The contri-

Address for correspondence: Anna Socha-Banasiak MD, Gastroenterology, Allergology and Pediatric Department, Polish Mother's Memorial Hospital - Research Institute, 281/289 Rzgowska St, 93-338 Lodz, Poland, phone: +48 4227113 41, fax: +48 42 271 13 40, e-mail: sochabanasiak@gmail.com

Received: 8.10.2016, accepted: 1.02.2017. 
bution of folate to DNA methylation and in consequence to the promotion of allergic airways disease development in animals was previously shown [8]. However, the influence of maternal folic acid intake prior to and during pregnancy on various types of allergy development in children is still not sufficiently clarified [10-16].

\section{Aim}

The aim of this study was to investigate the relationship between the occurrence of allergy (food allergy, inhalant allergy as well as combined allergy to food and inhalant allergens) in children and maternal folate intake prior to and during pregnancy. We examined the influence of the period and dosage of folate supplementation. To our knowledge, it is the first retrospective data analysis to report the effect of various daily dosages of folates ( $0.4 \mathrm{mg},>0.4 \mathrm{mg}$ ) taken by women in the preconception period as well as during the $1^{\text {st }}$ and $2^{\text {nd }} / 3^{\text {rd }}$ trimester of pregnancy on food allergy, inhalant allergy and combined allergy development in children aged 2-72 months.

\section{Material and methods}

\section{Study design and participants}

The retrospective study was performed in 307 children aged 2-72 months treated in the Pediatric Departments or Outpatient Clinics of the Polish Mother's Memorial Hospital - Research Institute in Lodz, between 2010 and 2014. The wide age range was established to enroll in the study the subjects with food allergy, inhalant allergy and combined allergy to food and inhalant allergens (usually the symptoms of sensitization to food allergens are observed in neonates and in younger subjects while inhalant allergy and combined allergy are diagnosed in the oldest children). The study group comprised 203 allergic and 104 healthy children (66.1\% and $33.9 \%$, respectively). Allergy was diagnosed based on medical history and physical examination of the patients and confirmed in the past by positive results of allergic blood tests: specific IgE (slgE) and/or skin prick tests (SPT) and double-blind, placebo-controlled food challenge (DBPCFC). Healthy children (without any allergy incidents in the past as well as any symptoms of allergy during physical examination) matched for sex and age were the control group. Between cases and controls there were no socio-demographic differences. The data concerning the preconception and pregnancy period as well as maternal folate supplementation were obtained directly from each mother using authors' own questionnaire. The analysis included the following data:

1. Perinatal period:

- Anemia during pregnancy (yes/no).

- Anemia treatment (yes/no), treatment method (iron, iron + folic acid).

- Prematurity (yes/no).
2. Breastfeeding (yes/no)

3. Occurrence of allergy in the family.

4. Mother's age, education level.

5. Prenatal exposure to tobacco smoke (passive smoking - cigarette smoking by mothers/other persons).

6. Occurrence of neural tube defects in the fetus in the previous pregnancy.

7. Maternal folate supplementation:

- Prior to pregnancy (yes/no, names of the supplement/medication).

- During pregnancy:

- $1^{\text {st }}$ trimester of pregnancy (yes/no, names of the supplement/medication).

- $2^{\text {nd }} / 3^{\text {rd }}$ trimester of pregnancy (yes/no, names of the supplement/medication).

The dosage of folate ( $\mu \mathrm{g} /$ day) in the preconception period and in the $1^{\text {st }}, 2^{\text {nd }} / 3^{\text {rd }}$ trimester was calculated using information on the package of a supplement/medication.

For the purpose of the study, formal written consent of parents and the approval of the Polish Mother's Memorial Hospital - Research Institute Ethics Committee were obtained (37/2011).

\section{Statistical analysis}

The main statistical parameters were calculated: minimum, maximum, arithmetic mean $(\bar{x})$ and standard deviation (SD). Normality of distribution was checked by the Shapiro Wilk test $(p=0.05)$. Differences between the groups were verified with the Student's t-test at the level of significance at $\alpha=0.05$. The incidence of particular values was calculated for features in nominal scale. A comparison among the groups was performed by means of the $\chi^{2}$ test.

\section{Results}

The age of the examined children ranged from 2 to 72 months including 92 (30\%) infants, 96 children in their $2^{\text {nd }}$, $3^{\text {th }}$ and $4^{\text {th }}$ year of life (31.3\%) and 119 children aged 4-6 years (38.7\%). The analysis of sex proportions among the studied children revealed more boys (60.3\%) than girls (39.7\%). No significant differences in the duration of pregnancy and breastfeeding between the study and control groups were observed $(p>0.05)$. During pregnancy, anemia was diagnosed in 52 mothers (15.8\% of mothers of allergic children and $19.2 \%$ of mothers of healthy children), while folic acid in a therapeutic dose with iron was taken only by 5 (9.6\%) mothers of children from the study and control groups ( $9.4 \%$ and $10.0 \%$, respectively, $p>0.05$ ). The occurrence of neural tube defects in the fetus in the past (previous pregnancy) was not reported by any of the mothers. During pregnancy allergic children and the healthy ones were equally exposed during the prenatal period to the, socalled, passive smoking (31.5\% vs. 34.6\%). Moreover, no significant differences in the mother's education level were noted between the studied groups ( $p>0.05$ ). 
Table 1. Characteristics of the studied population

\begin{tabular}{|c|c|c|c|c|c|c|}
\hline \multirow[t]{2}{*}{ Characteristic } & & \multicolumn{2}{|c|}{ Allergy group } & \multirow{2}{*}{$\begin{array}{l}\text { Significance of } \\
\text { differences }\end{array}$} & \multicolumn{2}{|c|}{ Non-allergy group } \\
\hline & & $n$ & $\%$ & & $n$ & $\%$ \\
\hline \multirow[t]{2}{*}{ Gender } & Girls & 79 & 38.9 & $p>0.05$ & 43 & 41.3 \\
\hline & Boys & 124 & 61.1 & & 61 & 58.7 \\
\hline \multirow[t]{2}{*}{ Gestation length [weeks] } & $\leq 37$ & 40 & 19.7 & $p>0.05$ & 21 & 20.2 \\
\hline & $>37$ & 163 & 80.3 & & 83 & 79.8 \\
\hline Breastfeeding & Yes & 169 & 83.2 & $p>0.05$ & 84 & 80.8 \\
\hline Anemia during pregnancy & Yes & 32 & 15.8 & $p>0.05$ & 20 & 19.2 \\
\hline \multirow[t]{2}{*}{ Treatment of anemia } & Iron & 22 & 68.7 & $p<0.05$ & 11 & 55.0 \\
\hline & Iron + folic acid & 3 & 9.4 & $p>0.05$ & 2 & 10.0 \\
\hline Children with neural tube defects in the past & Yes & - & - & & - & - \\
\hline \multirow[t]{6}{*}{ Family history of allergic diseases } & Yes & 135 & 66.5 & $p<0.001$ & 39 & 37.5 \\
\hline & Mother & 62 & 30.5 & $p<0.01$ & 17 & 16.3 \\
\hline & Father & 58 & 28.6 & $p<0.001$ & 12 & 11.5 \\
\hline & Siblings & 39 & 19.2 & $p<0.05$ & 10 & 9.6 \\
\hline & Grandparents & 63 & 31.0 & $p<0.001$ & 14 & 13.5 \\
\hline & No & 68 & 33.5 & $p<0.001$ & 65 & 62.5 \\
\hline Prenatal passive smoking (generally) & Yes & 64 & 31.5 & $p>0.05$ & 36 & 34.6 \\
\hline Prenatal passive smoking (smoking by mothers) & Yes & 9 & 14.1 & $p>0.05$ & 4 & 11.1 \\
\hline \multirow[t]{2}{*}{ Mother's age [years] } & $\leq 30$ & 74 & 36.5 & $p<0.05$ & 54 & 51.9 \\
\hline & $>30$ & 129 & 63.5 & & 50 & 48.1 \\
\hline \multirow[t]{4}{*}{ Mother's education level } & Higher education & 107 & 52.7 & $p>0.05$ & 61 & 58.7 \\
\hline & $\begin{array}{l}\text { Secondary } \\
\text { education }\end{array}$ & 78 & 38.4 & & 31 & 29.8 \\
\hline & $\begin{array}{l}\text { Vocational } \\
\text { education }\end{array}$ & 12 & 5.9 & & 7 & 6.7 \\
\hline & $\begin{array}{c}\text { Primary } \\
\text { education }\end{array}$ & 6 & 3.0 & & 5 & 4.8 \\
\hline \multirow[t]{3}{*}{ Type of allergy } & Inhalant & 77 & 37.9 & & - & - \\
\hline & Food & 77 & 37.9 & & - & - \\
\hline & Mixed & 49 & 24.2 & & - & - \\
\hline \multirow[t]{10}{*}{ Most common food and inhalant allergens } & Cow's milk & 82 & 40.4 & & - & - \\
\hline & Egg white & 22 & 10.8 & & - & - \\
\hline & Egg yolk & 19 & 9.3 & & - & - \\
\hline & Carrot & 4 & 2.0 & & - & - \\
\hline & House dust mite & 37 & 18.2 & & - & - \\
\hline & Cereal pollen & 33 & 16.2 & & - & - \\
\hline & Tree pollen & 18 & 8.9 & & - & - \\
\hline & Cat hair & 14 & 6.9 & & - & - \\
\hline & Dog hair & 13 & 6.4 & & - & - \\
\hline & Yeast & 9 & 4.4 & & - & - \\
\hline
\end{tabular}

$n$-number of children/mothers.

Food allergy was confirmed in 77 (37.9\%) children, inhalant allergy was identified also in 77 subjects, while allergy to inhalant and food allergens was diagnosed in $49(24.2 \%)$ children. The allergy tests in the past (SPT,
slgE) as well as DBPCFC confirmed sensitization to common allergens in children from the study group: cow's milk (40.4\%), egg white (10.8\%), egg yolk (9.3\%), carrot (2.0\%), house dust mite (18.2\%), cereal pollen (16.2\%), 
Table 2. Configuration of maternal folic acid intake in the preconception period and during pregnancy in the studied groups

\begin{tabular}{|c|c|c|c|c|c|c|}
\hline \multirow{3}{*}{$\begin{array}{l}\text { Maternal folic } \\
\text { acid intake }\end{array}$} & \multicolumn{6}{|c|}{ Mothers of children } \\
\hline & \multicolumn{2}{|c|}{ With allergy $=203$} & \multicolumn{2}{|c|}{ Without allergy = 104} & \multicolumn{2}{|c|}{ Total = 307} \\
\hline & $n$ & $\%$ & $n$ & $\%$ & $n$ & $\%$ \\
\hline 0 & 2 & $1.0^{*}$ & 13 & $12.5^{\star}$ & 15 & 4.9 \\
\hline 1 & 1 & 0.5 & 0 & 0.0 & 1 & 0.3 \\
\hline 2 & 25 & 12.3 & 21 & 20.2 & 46 & 15.0 \\
\hline 3 & 9 & 4.4 & 5 & 4.8 & 14 & 4.6 \\
\hline $1+2$ & 10 & $4.9^{*}$ & 12 & $11.6^{\star}$ & 22 & 7.1 \\
\hline $2+3$ & 80 & 39.4 & 33 & 31.7 & 113 & 36.8 \\
\hline $1+2+3$ & 76 & $37.5^{\star}$ & 20 & $19.2^{*}$ & 96 & 31.3 \\
\hline
\end{tabular}

${ }^{*} P<0.05$ statistical differences in frequency of maternal folate intake between the groups with allergy and without allergy in the following configuration: lack of supplementation (1.0 vs. 12.5), supplementation in the preconception period and in the $1^{\text {st }}$ trimester of pregnancy (4.9 vs. 11.6), supplementation in the preconception period and during the $1^{\text {st }}, 2^{\text {nd }}$ and $3^{\text {rd }}$ trimester of pregnancy $(37.5 \mathrm{vs} .19 .2) . n$-number of children, 0 -lack of supplementation, 1 - supplementation in the preconception period, 2 - supplementation in the $1^{\text {st }}$ trimester of pregnancy, 3 -supplementation in the $2^{\text {nd }}$ and $3^{\text {rd }}$ trimester of pregnancy.

Table 3. Differences in the frequency of maternal folate supplementation in dosages higher than recommended within the allergy group

\begin{tabular}{|c|c|c|c|c|c|c|c|c|c|}
\hline \multirow[t]{3}{*}{ Period } & \multicolumn{9}{|c|}{ Allergy group } \\
\hline & \multicolumn{3}{|c|}{ Food } & \multicolumn{3}{|c|}{ Inhalant } & \multicolumn{3}{|c|}{$\begin{array}{c}\text { Combined } \\
\text { (inhalant and food) }\end{array}$} \\
\hline & $n$ & $N$ & $N / n(\%)$ & $n$ & $N$ & $N / n(\%)$ & $n$ & $N$ & $N / n(\%)$ \\
\hline Preconception & 34 & 3 & 8.8 & 34 & 3 & 8.8 & 19 & 3 & 15.8 \\
\hline $1^{\text {st }}$ trimester & 74 & 29 & 39.2 & 71 & 21 & $29.6^{*}$ & 46 & 21 & $45.6^{\star}$ \\
\hline $2^{\text {nd }} / 3^{\text {rd }}$ trimester & 64 & 34 & $53.1^{*}$ & 60 & 28 & $46.7^{*}$ & 41 & 26 & $63.4^{*}$ \\
\hline
\end{tabular}

$n$-total number of mothers declaring folic acid supplementation within the studied group (food, inhalant or combined allergy) in the preconception period, $1^{\text {st }}$ and $2^{\text {nd }} / 3^{\text {rd }}$ trimester of pregnancy. $N$ - number of mothers declaring folic acid supplementation in dosages higher than recommended (> $400 \mu \mathrm{g} /$ day) within the studied group (food, inhalant or combined allergy) in the preconception period, $1^{\text {st }}$ and $2^{\text {nd }} / 3^{\text {rd }}$ trimester of pregnancy. ${ }^{*} P<0.05$ (in the $1^{\text {st }}$ trimester of pregnancy, differences between the groups with inhalant vs. combined allergy, in the $2^{\text {nd }} / 3^{\text {rd }}$ trimester of pregnancy, differences between the groups with food vs. combined allergy and inhalant vs. combined allergy).

tree pollen (8.9\%), cat hair (6.9\%), dog hair (6.4\%), and yeast $(4.4 \%)$. More cases of a family history with allergy episodes were confirmed in the allergic group $(n=135$, $66.5 \%)$ vs. the healthy children $(n=39,37.5 \%)(p<0.05)$ (Table 1).

Folate supplementation prior to or during pregnancy or during both of these periods was declared by a majority of the expectant mothers $(n=292,95.1 \%)$. The analysis of maternal folic acid intake in the studied groups indicated that mothers of allergic children declared folic acid supplementation both in the preconception period as well as during pregnancy more often than the mothers of healthy ones (37.5\% vs. $19.2 \%)(p<0.05)$ (Table 2$)$. A detailed analysis showed that in the preconception period, during the $1^{\text {st }}$ as well as the $2^{\text {nd }} / 3^{\text {th }}$ trimester of pregnancy, folic acid was more frequently supplemented by the mothers of allergic children (42.9\%, 94.1\%, 81.3\%) than the mothers of healthy children $(30.8 \%, 82.7 \%$, $55.8 \%$, respectively) $(p<0.05)$ (Figure 1 ). Comparison between the frequency of folic acid supplementation by mothers of children without any family history of aller- gic diseases from both the allergy group $(n=68)$ and the non-allergy group $(n=65)$ showed statistical differences $(p<0.05)$ only in the $2^{\text {nd }} / 3^{\text {rd }}$ trimester of pregnancy $(80.8 \%$ vs. $58.5 \%$, respectively). In the preconception period as well as in the $1^{\text {st }}$ trimester of pregnancy, the statistical differences between these groups were not observed (35.3\% vs. $29.2 \%$; $88.2 \%$ vs. $83.1 \%$, respectively).

What is more, some mothers used to take doses of folate higher than recommended. The doses exceeding $0.4 \mathrm{mg}$ /day were more often taken by the mothers of allergic children than the mothers of healthy ones in the $1^{\text {st }}(37.2 \%$ vs. $22.1 \%)$ as well as the $2^{\text {nd }} / 3^{\text {rd }}$ trimester of pregnancy (53.3\% vs. 39.6\%). The differences attained the level of statistical significance $(p<0.05)$. In the group of allergic children, folic acid in dosages higher than recommended was more frequently supplemented in the $2^{\text {nd }} / 3^{\text {rd }}$ trimester of pregnancy by the mothers of subjects with combined allergy than mothers of children with inhalant allergy (63.4\% vs. 46.7\%) and food allergy $(63.4 \%$ vs. $53.1 \%)(p<0.05)$. In the $1^{\text {st }}$ trimester of pregnancy statistical differences $(p<0.05)$ were observed between 
the groups with combined allergy and inhalant allergy (45.6\% vs. $29.6 \%$, respectively) (Table 3 ).

\section{Discussion}

Our results showed that maternal intake of folic acid prior to and during the $1^{\text {st }}$ as well as the $2^{\text {nd }} 3^{\text {rd }}$ trimester of pregnancy was positively associated with allergy development in offspring. To our knowledge, this is the first retrospective study to find that exposure to synthetic folate during all trimesters of pregnancy might be a risk factor for various types of allergy development in children aged 2-72 months. We analyzed both the period of maternal supplementation and dosage of synthetic folate. We observed that the mothers of allergic children used to take folic acid more often than the mothers of healthy children in both early and late pregnancy. Such relation, yet concerned only late pregnancy, was observed after excluding families with a history of atopy, which is a commonly known predisposing factor for developing inhalant/food allergy in children from such families. A plausible explanation for this is the utero exposure to a diet rich in methyl donors which reduce the expression of key genes that regulate the development of an adaptive immune response, increasing Th2 immunity and enhancing the heritable risk of developing allergic airways disease [8]. The influence of folate on fetal development was shown in the previous studies, however the fetal genomic regions that may be sensitive to methylation upper this agent have not been characterized. Amarasekera et al. [17] indicated differences in methylation in 2 immune cell types (CD4+ and antigen presenting cells) isolated from cord blood of high-folate and low-folate exposure offspring. The results of the study performed by Tavian et al. [18] showed that hematopoietic cell clusters appeared precisely in the human embryo between the $27^{\text {th }}$ and $40^{\text {th }}$ days of development, which suggests the possibility of early impact of methylation processes on T-cell differentiation [15]. In our study, in the group of children without a family history of allergic diseases, the differences in folate supplementation by mothers from the study and control groups was noted only in the $2^{\text {nd }} / 3^{\text {th }}$ trimester of pregnancy, which may indicate that late pregnancy is a critical period for immune development in offspring. It was previously shown that after the first trimester of pregnancy the rise in the exposure to immunoglobulin $\mathrm{E}$ and IgE receptor activity in fetus was noticed. Moreover, low-affinity IgE receptors (CD23) were expressed in the fetal gut from 16 weeks of gestation, but not from 11 to 16 weeks. It was also found that during the $2^{\text {nd }}$ trimester of pregnancy, human amniotic fluid contained intact lgE at levels that increased and correlate with maternal circulating lgE levels $[11,19]$. These arguments are crucial to explain the role of high dosages of folates taken by mothers in allergy development in offspring that was noted in our study. Other authors also

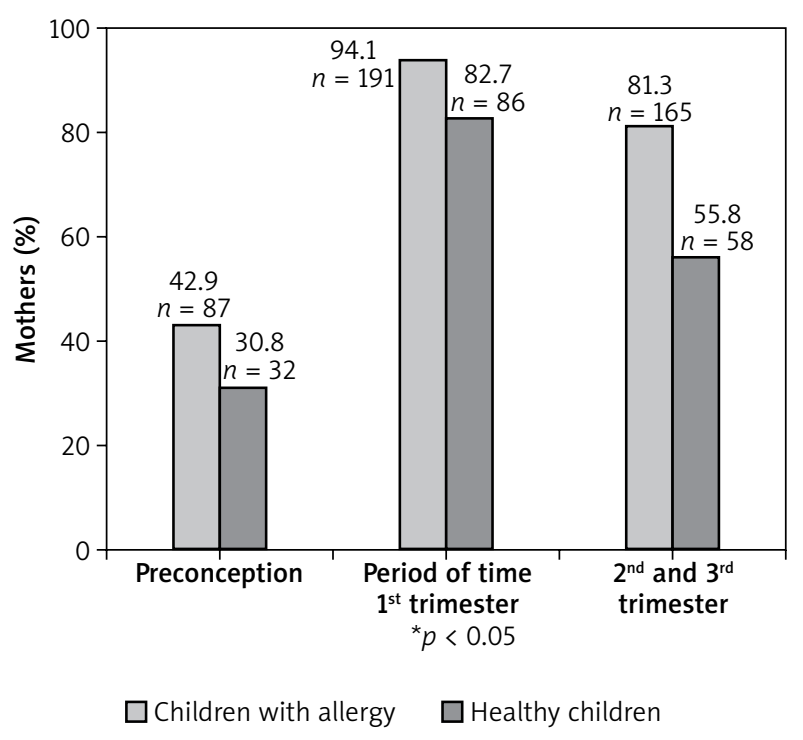

Figure 1. Percentage of mothers declaring folic acid supplementation prior to and during pregnancy

observed the correlation between a higher than recommended folate maternal supplementation and asthma or eczema development in children [11,20]. Results of the case-control study together with meta-analysis performed by Yang et al. [12] indicated the dose-dependent effect of folates. A high dosage of maternal folic acid supplementation during pregnancy was associated with an increased risk of infant asthma, whereas supplementation with a relatively low dosage was associated with a decreased risk of this disease.

The principal novelty in our study was an indication that fetal exposure to synthetic folic acid is a risk factor for the development of various types of allergy. We also showed that the mothers of children with allergy to both food and inhalant allergens used to take folic acid more often in dosages $>0.4 \mathrm{mg} /$ day than the remaining mothers. The previous studies focused on the examination of the agent's influence on only one allergy manifestation. Our results suggest that especially concomitance of symptoms from the respiratory tracts and the digestive system may be an effect of heavy methyl donor fetal exposure. However, we are aware that other genetic and environmental factors play a role in these processes. In our observation maternal folate supplementation in dosages higher than recommended is a result of taking by some women folate both as a separate vitamin and as multivitamin supplements containing the same. As a result, the total dose of folate taken was higher than recommended (i.e. $0.4 \mathrm{mg} /$ day).

In our study the analysis of dietary maternal folic acid intake was not performed. In the previous study the authors showed the effect of folic acid intake on allergy development as taken in a synthetic form but not when sourced from a diet [11]. It was recognized that bioavail- 
ability of natural and synthetic folate is different. The polyglutamate form from food has a lower bioavailability than monoglutamate form from supplements [11, 16].

There are some limitations of our study. We examined the influence of maternal folate intake on allergy development in offspring, however we are aware of the fact that folic acid is only one factor that contributes to epigenetic modifications and this way it may increase the risk of allergy development. Further multifactorial analyses are necessary to indicate other agents taking part in these processes. Moreover, our results were based on a retrospective analysis and the examination of serum folate concentration in women during pregnancy as well as in children after birth and during childhood was not performed. Serum folic acid concentration depends not only on vitamin intake but also on folate metabolism that vary depending on some enzymes activity, MTHFR included. However, our results clearly indicate the relationship between maternal folic acid intake and an increasing risk of allergy development in children. In our opinion, further research is needed to explain the mechanism of the observed phenomena on a molecular level.

\section{Conclusions}

It should be emphasized that the synthetic folic acid is an agent that might contribute to epigenetic modifications during fetal development. Maternal folic acid supplementation in dosages higher than recommended may be a risk factor for allergy development in offspring, especially with the coincidence of symptoms from respiratory and digestive systems. Taking into account the increase of maternal folic acid supplementation in the general population over the last years, including supplementation in dosages higher than recommended especially after the $1^{\text {st }}$ trimester of pregnancy, the enhanced frequency of allergic diseases in the studied children may be partially connected with the increased frequency of allergy development in the entire population. However, other factors may also lead to this phenomenon. We would like to emphasize that future research in a larger group of subjects is necessary to confirm our results.

\section{Acknowledgments}

The study was performed in the Gastroenterology, Allergology and Pediatric Department and Outpatient Clinics of the Polish Mother's Memorial Hospital Research Institute.

This project was funded by a Polish Ministry of Science \& Higher Education, Polish Mother's Memorial Hospital - Research Institute - Young Researcher Internal Grant no 2011/IV/22-MN.

\section{Conflict of interest}

The authors declare no conflict of interest.

\section{References}

1. Czeizel A, Dudás I, Vereczkey A, Bánhidy F. Folate deficiency and folic acid supplementation: the prevention of neuraltube defects and congenital heart defects. Nutrients 2013; 5: 4760-75

2. Cawley S, Mullaney L, McKeating A, et al. A review of European guidelines on periconceptional folic acid supplementation. Eur J Clin Nutr 2016; 70: 143-54.

3. Brzeziński Z. Neural tube defects primary prevention programme in Poland. Med Wieku Rozw 1999; 3: 503-8.

4. Prevention of neural tube defects: results of the Medical Research Council Vitamin Study. MRC Vitamin Study Research Group. Lancet 1991; 338: 131-7.

5. Greenberg J, Bell S, Guan Y, Yu Y. Folic acid supplementation and pregnancy: more than just neural tube defect prevention. Rev Obstet Gynecol 2011; 4: 52-9.

6. Moephuli S, Klein N, Baldwin M, Krider H. Effects of methionine on the cytoplasmic distribution of actin and tubulin during neural tube closure in rat embryos. Proc Natl Acad Sci USA 1997; 94: 543-8.

7. Okupa A, Lemanske R Jr, Jackson D, et al. Early-life folate levels are associated with incident allergic sensitization. J Allergy Clin Immunol 2013; 131: 226-8.e1-2.

8. Hollingsworth J, Maruoka S, Boon K, et al. In utero supplementation with methyl donors enhances allergic airway disease in mice. J Clin Invest 2008; 118: 3462-9.

9. Prescott S, Clifton V. Asthma and pregnancy: emerging evidence of epigenetic interactions in utero. Curr Opin Allergy Clin Immunol 2009; 9: 417-26.

10. Håberg S, London S, Nafstad P, et al. Maternal folate levels in pregnancy and asthma in children at age 3 years. J Allergy Clin Immunol 2011; 127: 262-4.

11. Whitrow M, Moore V, Rumbold A, Davies M. Effect of supplemental folic acid in pregnancy on childhood asthma: a prospective birth cohort study. Am J Epidemiol 2009; 170: 1486-93.

12. Yang L, Jiang L, Bi M, et al. High dose of maternal folic acid supplementation is associated to infant asthma. Food Chem Toxicol 2015; 75: 88-93.

13. Magdelijns F, Mommers M, Penders J, et al. Folic acid use in pregnancy and the development of atopy, asthma, and lung function in childhood. Pediatrics 2011; 128: e135-44.

14. Brown S, Reeves K, Bertone-Johnson E. Maternal folate exposure in pregnancy and childhood asthma and allergy: a systematic review. Nutr Rev 2014; 72: 55-64.

15. Håberg S, London S, Stigum H, et al. Folic acid supplements in pregnancy and early childhood respiratory health. Arch Dis Child 2009; 94: 180-4.

16. van der Valk R, Kiefte-de Jong J, Sonnenschein-van der Voort A,et al. Neonatal folate, homocysteine, vitamin B12 levels and methylenetetrahydrofolate reductase variants in childhood asthma and eczema. Allergy 2013; 68: 788-95.

17. Amarasekera M, Martino D, Ashley S, et al. Genome-wide DNA methylation profiling identifies a folate-sensitive region of differential methylation upstream of ZFP57-imprinting regulator in humans. FASEB J 2014; 28: 4068-76.

18. Tavian M, Biasch K, Sinka L, et al. Embryonic origin of human hematopoiesis. Int J Dev Biol 2010; 54: 1061-5.

19. Thornton C, Holloway J, Popplewell E, et al. Fetal exposure to intact immunoglobulin E occurs via the gastrointestinal tract. Clin Exp Allergy 2003; 33: 306-11.

20. Dunstan J, West C, McCarthy S, et al. The relationship between maternal folate status in pregnancy, cord blood folate levels, and allergic outcomes in early childhood. Allergy 2012; 67: 50-7. 